\title{
An outpatient "evolution" in orthopedic surgery
}

\author{
Cite as: CMAJ 2017 December 18;189:E1568. doi: 10.1503/cmaj.109-5534
}

Posted on cmajnews.com on Nov. 29, 2017.

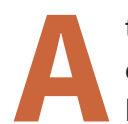
t a time when the Ontario government is reopening mothballed hospitals to meet demand for beds, a group of Ottawa surgeons is pushing to free beds by discharging patients more quickly after hip and knee replacement operations.

"Until recently, our patients all spent at least a few days, sometimes more, in hospital," said Dr. Paul Beale, an orthopedic surgeon at The Ottawa Hospital. "Now, we're sending an increasing number of patients home on the same day they're operated on."

Many hospitals are running at overcapacity and cancel joint replacement operations owing to a lack of beds, added Beale. With more than 50000 hip and knee replacements conducted every year in Canada, the potential to liberate hospital beds is considerable.

"Currently, outpatients comprise about $10 \%$ of the people we operate on," he said. "But with very careful management, we think this ratio could reach as high as $30 \%$. It's a major evolution in orthopedic surgery. And it's here to stay."

Beale's enthusiasm is backed by a growing body of research originating in cost-reduction efforts by American hospitals. In a 2016 paper, a group of surgeons from Missouri explained that innovations in pain control, regional anesthesia and rehabilitation, among other advances, now allow patients to return home sooner. Surgeons, practice administrators, anesthesiologists, nurses, physical and occupational therapists, case managers, and post-acute care providers all have roles to play, suggested the authors.

Canadian researchers are adding to these findings. In a study published last February, researchers at the Ottawa Hospi-

tal found that outpatient care for patients who had undergone total knee replacement was about $30 \%$ cheaper than inpatient care, with no difference in the quality of care noted within a year of surgery. "The savings came primarily from costs associated with the inpatient encounter, such as surgical ward, pharmacy and patient meal costs," the study concluded.

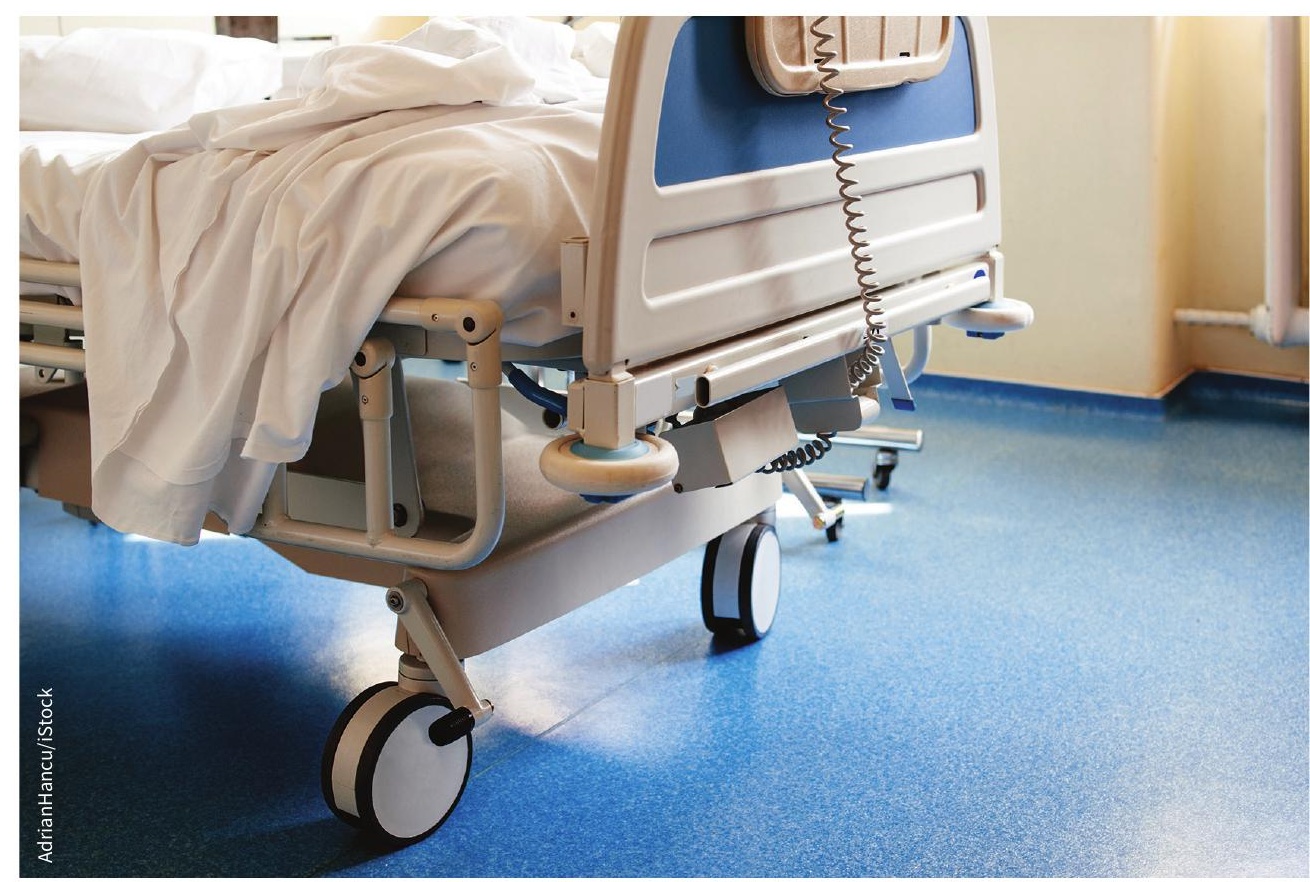

Sending patients home sooner after orthopedic surgery frees hospital beds.

Another study, by researchers at the Jewish General Hospital in Montréal, found that hospital discharge within two days of total knee or hip replacement wasn't associated with increased 30-day major complications and readmissions compared to patients discharged three or four days after surgery. There were higher rates of 30-day complications and readmissions, however, among patients who were discharged to an extended care facility rather than to their home.

But "early discharge within the first two days postoperatively for risk-stratified patients appears feasible without compromising patient care," said study coauthor Dr. John Antoniou, the incoming president of the Canadian Orthopaedic Association. 